\title{
INDUGTION OF OVULATION IN THE LION, PANTHERA LEO
}

\author{
I. W. ROWLANDS AND R. M. F. S. SADLEIR* \\ Wellcome Institute of Comparative Physiology, \\ Zoological Society of London, Regent's Park, London
}

(Received 4th Fuly 1967)

\begin{abstract}
Summary. Three lionesses of different ages were injected intramuscularly with 1600 i.u. PMSG and, 3 days afterwards, with 1000 i.u. HCG. The reproductive organs were examined 2 days later; eggs were recovered from the Fallopian tubes of two of the animals, one of which had superovulated. The ovaries of the third, much younger lioness contained numerous intact follicles.

The endometrium of the two lionesses which had ovulated contained numerous glands with some degree of coiling and the vaginal epithelium was cornified. The vaginal smear of the un-ovulated animal indicated a pro-oestrous condition.
\end{abstract}

\section{INTRODUCTION}

Lions have been kept for many hundreds of years in captivity where they have bred regularly. Breeding among other large felids in similar conditions is uncommon, although quite recently successes have been reported in the tiger (P. tigris) by Sankhala (1967) and Thornton, Yeung \& Sankhala (1967), jaguar ( $P$. onca) by Hunt (1967) and cheetah (Acinonyx jubatus) by Florio \& Spinelli (1967). Sankhala has noted that the failure of several tigers to breed is the result of the incompatibility of some males with all available females, so that their infertility cannot be attributed to any physiological abnormality.

Knowledge of the reproductive processes in the lion is confined to information which can be gleaned from observable external events associated with breeding. The gestation period, litter size and the periodicity and duration of oestrus have been well documented (Cooper, 1942; Steyn, 1951; Sadleir, 1966) and provide useful information on which to base a physiological investigation such as we have undertaken on the induction of ovulation. Moreover, as the felids form a relatively un-divergent family of carnivores, it may be expected that information on the hormonal requirements for ovulation in the lion would form a useful basis for the artificial stimulation of fertility in other species of the group. From time to time in zoological collections circumstances make it necessary to put an animal to death painlessly or to spay an animal. The opportunity was taken to observe three such lions treated by methods used

\footnotetext{
* Present address: Department of Biological Sciences, Simon Fraser University, Burnaby 2 B.C., Canada.
} 
routinely in human and veterinary medicine for stimulating ovulation, the treatment being given just before the animals were due to be killed. The small number (three) of animals available precluded the use of any as controls and we have had to rely on breeding records to estimate the normal ovulation rate and the age of puberty.

Steyn (1951) who analysed the records of 323 litters of lions born in four zoos (Dublin, Leipzig, London and Pretoria) has reported a mean litter size of $3 \cdot 0 \pm 1 \cdot 1$ cubs. The corresponding figures given by Grabianska \& Wolinski (1957) for twenty-four and forty-six litters born in two Polish zoos are 2.3 and 3.4 and a mean litter size of 2.6 cubs was recorded for ten recent litters in London. For wild lions, Schenkel (1966) reported five litters of three, three, three, three and five cubs respectively. The range of litter sizes would, therefore, seem to be from one to six and making some allowance for pre-natal loss, the maximum number of ova ovulated would be expected to be about eight.

Lions have been reported to reach puberty at varying ages. Steyn (1951) commented that males and females have been known to breed before 2 years of age but, more generally, females do not become sexually active before they are 3 to 4 , and males before they are 5 to 6 years old. Cooper (1942) reports puberty in the female at 24 to 28 months but Went (1963) has pointed out that the effective age of puberty largely depends on the actual age at which the sexes are first joined. He calculated that the age at which four lionesses first conceived was $30 \frac{1}{2}, 30 \frac{1}{2}, 31 \frac{1}{2}$ and $34 \frac{1}{2}$ months, and the age of five males at the time of first fertile mating to be $27 \frac{1}{2}, 28 \frac{1}{2}, 33 \frac{1}{2}, 35 \frac{1}{2}$ and $35 \frac{1}{2}$ months. A pair of litter mates in London kept together from birth mated for the first time at 33 months (1008 days). This mating was not fertile but the subsequent one, 45 days later, resulted in conception and birth of a litter. The age of puberty in lions would seem to fall between their 2nd and 3rd year of life.

\section{MATERIALS AND METHODS}

The history and schedule of hormonal injections of the three lionesses were as follows:

Lioness A received as a sub-adult on 25th October 1957. She had regular oestrous cycles while with a male from March 1964 which ceased in November 1964. Became sway-backed and unsuitable for exhibition. Injected 1600 i.u. PMSG at 10.30 hours on 12th February and 1000 i.u. HCG at 12.40 hours on 15th February 1965. Killed 09.50 hours on 17th February 1965.

Lioness B was born London Zoo, 10th August 1962. No reproductive behaviour seen. Developed hyperthyroidism and became unfit for exhibition. Injected 1600 i.u. PMSG at 10.20 hours on 17th April 1965 and 1000 i.u. HGG at 09.20 hours on 20th April 1965. Killed 09.25 hours on 22nd April 1965.

Lioness C was born Jersey Zoo, 4th September 1965. No reproductive behaviour seen. Bilateral ovariectomy at request of owners. Injected 1600 i.u. PMSG at 10.10 hours on 9th September 1966 and 1000 i.u. HGG at 09.30 hours on 12th September 1966. Ovariectomy at 12.00 hours on 14th September 1966.

These animals were placed in a crush-box for injections which were given intramuscularly. 
The reproductive organs of Lionesses $\mathrm{A}$ and $\mathrm{B}$ were removed and photographed. The ovaries were dissected and fixed in Bouin's solution, and the Fallopian tubes flushed with saline to recover any eggs. When necessary the cumulus oophorus was digested with hyaluronidase to permit accurate counting and, afterwards, the eggs were fixed in formol saline. Reproductive tracts were fixed in $10 \%$ formalin and representative sections, cut at $5 \mu$, were stained in haematoxylin and eosin. The ovaries of Lionesses $\mathbf{A}$ and $\mathbf{C}$ were serially sectioned at $5 \mu$ and every tenth section mounted. The dimensions of some of the tubal eggs were measured using an eye-piece scale calibrated to a slide micrometer. Follicles of Lioness $\mathrm{G}$ were measured in three dimensions by the method described by Rowlands (1956) for the corpora lutea of the guinea-pig.

\section{RESULTS}

The results obtained on the three lionesses are recorded independently below.

Lioness $A$. At post-mortem examination, both ovaries measured $3 \times 1.7 \mathrm{~cm}$. The left ovary contained one very large $(12 \times 16 \mathrm{~mm})$, recently ovulated follicle which was distended and highly vascular. It also contained at least three unruptured follicles up to $5 \mathrm{~mm}$ diameter. The right ovary contained one recently ruptured follicle of similar size and appearance to that in the left ovary, one large translucent unruptured follicle and one well-organized corpus luteum.

Histological examination of the left ovary revealed a second ovulation, in a non-protuberant follicle, one old corpus luteum and several small cystic follicles. Two of three ruptured follicles contained in these two ovaries were of uneven outline due to compression by large adjacent follicles. The cavity of the ruptured follicles had become partly obliterated by the thickening and folding of the granulosa layer as shown in Pl. 1, Fig. 1. In all three spent follicles the point of rupture had sealed and the antrum was filled with fluid. The folded granulosa was very highly vascularized, and the cells were spindle-shaped, the nuclei being small, rounded and apparently inactive. There was no evidence of cell division or of luteinization. The membrana granulosa of the unruptured follicle was slightly increased in thickness but was not folded. The blood supply to this follicle was much less than that of the ovulated follicle and there was little or no vascular development (Pl. 1, Fig. 2).

One egg was recovered from the washings of each oviduct. That from the right tube was surrounded by a dense cumulus while that from the left tube was completely denuded. This egg had a vitelline diameter of $130 \mu$ and a zona pellucida of about $30 \mu$ in thickness (Pl. 1, Fig. 3). These facts suggested that ovulation in the two ovaries was not simultaneous.

Macroscopically, the uterine horns were about $1 \mathrm{~cm}$ in diameter and distinct coiling of the endometrium within the myometrium could be seen; this was confirmed in histological sections. The endometrium contained many glands opening into the uterine lumen and extending basally in a slightly coiled fashion. The glandular epithelium was columnar and nearly obliterated the lumen. There was little evidence of secretory activity (Pl. 1, Fig. 4). The vaginal epithelium was convoluted and heavily cornified. The vulva was slightly swollen and everted, and pink in colour (Pl. 1, Fig. 5). 
Lioness $B$. Both ovaries measured $4 \times 2 \mathrm{~cm}$ and the surface of each was studded with small bright-red follicles which had recently ovulated. The left ovary contained twenty-one ovulated follicles of which one was much larger than the rest and had a slit-like rupture point 4 to $5 \mathrm{~mm}$ in length. This ovary also contained one protuberant, but unruptured follicle of about $7 \mathrm{~mm}$ diameter (Pl. 1, Fig. 6). The right ovary contained thirteen ovulated follicles, four of which were much larger than the remainder, and also two large unruptured follicles. Histological examination confirmed these findings and indicated the explosive nature of the response in the ovaries. The rupture points were large and herniation of the membrana granulosa had occurred (Pl. 2, Fig. 1). The membrana granulosa of the spent follicles was disorganized and less vascular than that of Lioness A, and almost filled the antrum; there was little fluid present.

The unruptured follicles, including numerous small ones, were not affected by the treatment. The macroscopic appearance of the uterine horns was similar to that of Lioness A. The cervix was large and muscular and from the vaginal aspect it was complexly tesselated with no discernible os. Histologically, each endometrial gland was found to possess a large straight neck and a considerable degree of coiling at the base (Pl. 2, Fig. 2). The glandular epithelium was columnar and in the coiled region the glands had a prominent lumen although there was little evidence of secretory activity. The vaginal epithelium was cornified. Longitudinal section of the cervical region of the tract (P1. 2, Fig. 3) showed that the cornification extended throughout the length of the cervix and for a short distance into the uterus. A transverse section of the lower vagina is shown in Pl. 2, Fig. 4.

A total of thirty-four eggs was recovered in washings of the Fallopian tubes. The left tube contained twenty-four eggs of which four were denuded of all cellular attachment and twenty were present in a large mass of cumulus. The right tube contained ten eggs, of which three were denuded and seven in cumulus. The average vitelline diameter of the denuded eggs was $130 \mu$; the thickness of the zona was $30 \mu$.

Lioness $C$. There was no evidence from macroscopic examination of the ovaries that ovulation had occurred but the presence of at least ten large, thin-walled, translucent follicles (up to $5 \mathrm{~mm}$ in diameter) in each ovary indicated a considerable amount of stimulation. During the removal of the left ovary two of the large follicles ruptured while being handled and follicular fluid was extruded under considerable pressure.

\section{EXPLANATION OF PLATE 1}

FIG. 1. Left ovary of Lioness A, showing one large ruptured and three intact follicles. $\times 7$. Fig. 2. Part of wall of the adjacent ruptured and intact follicles seen in Fig. 1 showing vascular development following ovulation. $\times 100$.

Frg. 3. Tubal egg of Lioness A. $\times 300$.

Fig. 4. Uterine horn of Lioness A showing glandular development of the endometrium. $\times 10$.

FIG. 5. Vulva of Lioness A. $\times 0.75$.

Fig. 6. Right ovary of Lioness B, re-photographed from colour transparency, to show large and many small ruptured follicles. $\times 1 \cdot 5$. 
PLATE:

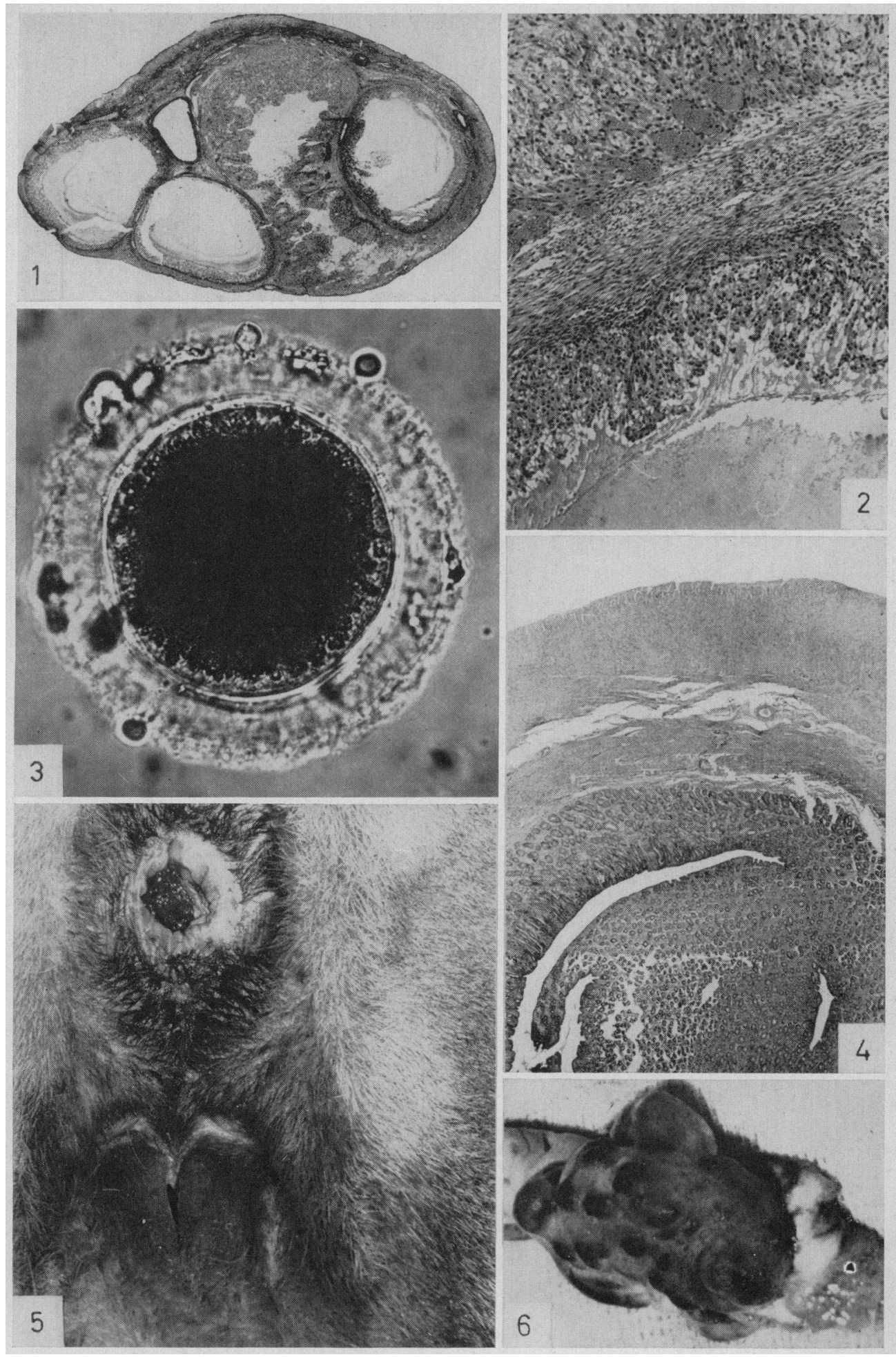

fiacing 6.108 
PLATE 2

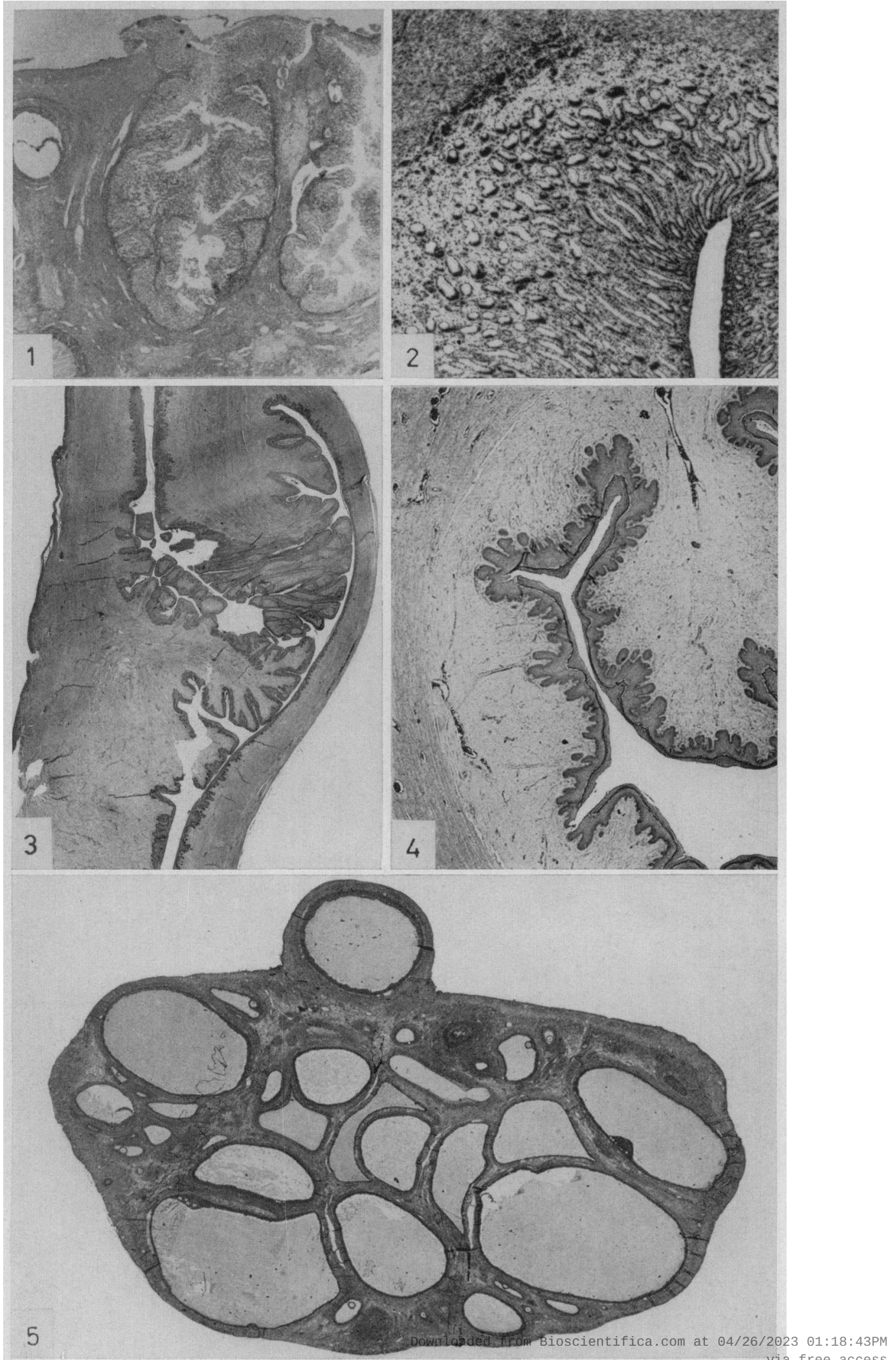

Facing p. 109 
The histological sections (see Pl. 2, Fig. 5) confirmed the highly follicular nature of the response of this lioness to the injected hormones and that ovulation had not occurred. There was no sign of 'luteinization' in any of the follicles. The two accidentally ruptured follicles were clearly visible and a considerable haemorrhage had occurred at these two sites which made serial sectioning very difficult. There was no evidence of a previous ovulation.

A total of seventy-one follicles was measured. Of these, sixty-four were measured in three dimensions as indicated on p. 107 and Table 1 gives the distribution of their diameters. The mean diameter of another seven follicles in the left ovary was calculated from measurements of their two largest diameters at right angles, in that portion of the ovary of which serial sections would not be mounted. The mean diameter of these follicles was $3 \cdot 1,3 \cdot 2,3 \cdot 4,3 \cdot 4,3 \cdot 5,3 \cdot 6$ and $4.8 \mathrm{~mm}$.

TABLE 1

DISTRIBUTION OF FOLLIGLE SIZES IN OVARIES OF LIONESS G

\begin{tabular}{l|c|c|c|c|c|c|c|c|c|c|c}
\hline & \multicolumn{10}{|c}{ No. of follicles in each diameter $(\mathrm{mm})$ class } \\
\cline { 2 - 9 } & $0 \cdot 5$ & $1 \cdot 0$ & $1 \cdot 5$ & $2 \cdot 0$ & $2 \cdot 5$ & $3 \cdot 0$ & $3 \cdot 5$ & $4 \cdot 0$ & $4 \cdot 5$ & $5 \cdot 0$ \\
& to & $t o$ & $t o$ & to & to & to & to & to & to & 10 \\
& $0 \cdot 9$ & $1 \cdot 4$ & $1 \cdot 9$ & $2 \cdot 4$ & $2 \cdot 9$ & $3 \cdot 4$ & $3 \cdot 9$ & $4 \cdot 4$ & $4 \cdot 9$ & $5 \cdot 4$ \\
\hline Left ovary & 3 & 4 & 9 & 8 & 1 & 2 & 1 & 1 & 0 & 0 \\
Right ovary & 6 & 7 & 11 & 2 & 2 & 2 & 2 & 1 & 1 & 1 \\
Total & 9 & 11 & 20 & 10 & 3 & 4 & 3 & 2 & 1 & 1 \\
\hline
\end{tabular}

Only the tip of the uterine horn of this animal was available for examination. Sections show only a slight amount of glandular development of the endometrium, but mitotic figures were frequent in the epithelial cells of the glands.

A vaginal smear taken at operation contained a high proportion of small, nucleolated, epithelial cells and a few cornified, epithelial cells, indicative of a pro-oestrous condition.

\section{DISGUSSION}

The age and reproductive state of these three animals at the onset of treatment were clearly not comparable: Lioness $A$ was a non-parous adult which had cycled, Lioness B was 2 years 9 months old and, as far as can be judged, was approaching puberty (see p. 106), and Lioness G, being only 1 year old, was immature.

\section{EXPLANATION OF PLATE 2}

FIG. 1. Right ovary of Lioness B showing two small ruptured follicles, to indicate the explosive nature of ovulation-large rupture point and extrusion of membrana granulosa. $\times 17$.

FIG. 2. Uterus of Lioness B showing coiling of endometrial glands. $\times 30$.

FIG. 3. Longitudinal section of cervical region of Lioness $B$, with uterus uppermost. $\times 4$.

FIG. 4. Transverse section of lower vagina of Lioness $B$, showing cornified epithelium. $\times 20$.

FIG. 5. Ovary of Lioness $\mathrm{C}$ indicating a follicular response only. $\times 18$. 
The response obtained in Lioness A, culminating in the rupture of three follicles, was considered to be within normal physiological range. For this reason, the other two animals were treated similarly and the results in both have indicated that follicle stimulation was excessive. There can be little doubt that in Lioness C (immature) the follicular response may be attributed to the injected PMSG but, as Lioness B may have been approaching her first oestrus, it is possible that endogenous FsH contributed to the response.

The finding of tubal eggs surrounded by cumulus cells in Lionesses A and B suggests that ovulation had occurred very shortly before death, that is, about $48 \mathrm{hr}$ after injection of HCG. The exact interval cannot be determined, and, as far as we are aware, it has not been determined in any other carnivores. On the other hand, the interval between coitus and ovulation has been determined in the ferret ( $30 \mathrm{hr}$, Hammond \& Walton, 1934) and domestic cat (24 hr to $54 \mathrm{hr}$, for references see Asdell, 1964). Many suggestions may be made to account for the failure of Lioness $\mathrm{G}$ to ovulate. It is possible that (a) the interval of $48 \mathrm{hr}$ between injection of HCG and ovariectomy was too short, (b) the dosage of the hormone was ineffective in view of the large numbers of stimulated follicles, (c) the follicles were not in a condition to rupture and (d) individual variation in response may be considerable. Intravenous injection of HGG, which is the most effective route to induce ovulation in other mammals, was not practicable in the conscious lion.

There is a great dearth of detailed information about reproduction in large carnivores and data such as the size of the Graafian follicle before ovulation are almost non-existent. It is impossible, therefore, to compare the size of the follicles in Lioness C with that of the normal follicle of oestrus. Duke (1949) measured the largest follicle present in the ovaries of the bobcat (Felis rufa). This species breeds in the spring when the largest follicles recorded were $5.5 \mathrm{~mm}$ in diameter, and are, therefore, comparable in size to the largest follicle stimulated in Lioness $\mathrm{G}$, excluding the two very large follicles which were accidentally ruptured.

The vitelline diameter $(130 \mu)$ of the four eggs measured before fixation, fell inside the range of ovum size normally found in eutherian mammals (120 to $150 \mu$, Austin \& Bishop, 1957). The deutoplasm of the vitellus of all the eggs examined was heavily laden with lipoid material giving it a frothy appearance. The zona pellucida was thicker than that of other mammals known to us and had a very irregular outer margin. In overall aspect, the lion egg is very similar to that of the cat as figured by Boyd \& Hamilton (1952, Fig. 14.5). These two species differ, however, with regard to the period of retention of the corona radiata following ovulation, as in the lion it appears to disperse rapidly.

The histological appearance of the endometrium and vaginal epithelium of Lionesses A and B was closely similar and there was little doubt that the hormonal treatment induced a condition in these organs exactly similar to that in the oestrous cat (Dawson \& Kosters, 1944). As these two lions were kept in isolation during the experiment no opportunity was given to observe oestrous behaviour. The reactions seen in the reproductive tract of Lioness $\mathrm{C}$, which did not ovulate, were much less intense. But as only the tip of the uterine horn was available for examination and the animal was much below the age of puberty, 
the complete response could not be observed. The vaginal smear, however, indicated a similar pro-oestrous condition to that reported by Liché \& Wodzicki (1939).

These observations were carried out on a species which is not normally available for investigation and it is hoped that, if similar opportunities occur in the future, further studies of this nature will lead to the fuller understanding of the reproductive physiology of this and other large carnivores.

\section{ACKNOWLEDGMENTS}

We are grateful to $\mathrm{Mr}$ Oliver Graham-Jones, F.R.c.V.s., the former Senior Veterinary Officer, and his staff for their assistance with this work, and to the Head Keeper and Keepers of the Lion House for information. We should also like to thank the Jersey Wildlife Preservation Trust for their kind permission to use Lioness $\mathrm{G}$ in this investigation.

\section{REFERENCES}

Asdell, S. A. (1964) Patterns of mammalian reproduction, 2nd edn. Constable, London. Austin, C. R. \& Bishop, M. W. H. (1957) Fertilisation in mammals. Biol. Rev. 32, 296.

Boyd, J. D. \& Hamilton, W. J. (1952) Cleavage, early development and implantation of the egg. In: Marshall's Physiology of Reproduction, Vol. 2, 3rd edn. Ed. A. S. Parkes. Longmans, Green, London.

Cooper, J. B. (1942) An exploratory study on African lions. Comp. Psychol. Monogr. 17, No. 7, 1.

Dawson, A. B. \& Kosters, B. A. (1944) Pre-implantation changes in the uterine mucosa of the cat. Am. F. Anat. 79, 241.

Duke, K. L. (1949) Some notes on the histology of the ovary of the bobcat (lynx) with special reference to the corpora lutea. Anat. Rec. 103, 111.

Florio, P. L. \& SPLNELli, L. (1967) Successful breeding of a cheetah Acinonyx jubatus in a private zoo. Int. Zoo $\mathrm{Yb} .7,150$.

Grabiańska, E. \& Woliński, Z. (1957) Chów lwów w ogrodach zoologicznych w Polsce w latach 1952-1955. Przegl. zool. 1, 259.

Hammond, J. \& Walton, A. (1934) Notes on ovulation and fertilization in the ferret. F. exp. Biol. 11, 307.

HUNT, H. (1967) Growth rate of a new-born hand-reared jaguar Panthera onca in Topeka Zoo. Int. Zoo Yb. 7, 147.

LichE, H. \& WoDzICKI, K. (1939) Vaginal smears and the oestrous cycle of the cat and lioness. Nature, Lond. 144, 245.

Rowlands, I. W. (1956) The corpus luteum of the guinea-pig. Ciba Fdn Colloq. Ageing, 2, 69.

SADLEIR, R. M. F. S. (1966) Investigations into the reproduction of larger Felidae in captivity. $\mathcal{F}$. Reprod. Fert. 12, 411.

Sankhala, K. S. (1967) Breeding behaviour of the tiger Panthera tigris in Rajasthan. Int. Zoo rb. 7, 133.

Schenkel, R. (1966) Play, exploration and territoriality in the wild lion. Symp. zool. Soc. Lond. 18, 11.

Steyn, T. J. (1951) The breeding of lions in captivity. Fauna and Flora, Pretoria, 2, 37.

Thornton, I. W. B., Yeung, K. K. \& Sankhala, K. S. (1967) The genetics of the white tigers of Rewa. J. Zool., Lond. 152, 127.

Went, A. E. J. (1963) Breeding of lions in the Dublin Zoo (1857-1962). Scient. Proc. R. Dubl. Soc. Ser. B, 1,67 . 